\title{
Synthesis of Highly-Selective Fibrous Adsorbent by Introducing 2-Ethylhexyl Hydrogen-2-Ethylhexylphosphonate for Scandium Adsorption
}

\author{
Hiroyuki Hoshina*, Yuji Ueki, Seiichi Saiki, Noriaki Seko \\ Environment and Industrial Materials Research Division, Quantum Beam Science Center, Sector of Nuclear \\ Science Research, Japan Atomic Energy Agency, Takasaki, Japan \\ Email: ${ }^{*}$ hoshina.hiroyuki@jaea.go.jp
}

Received 1 July 2014; revised 19 August 2014; accepted 31 August 2014

Copyright (C) 2014 by authors and Scientific Research Publishing Inc.

This work is licensed under the Creative Commons Attribution International License (CC BY).

http://creativecommons.org/licenses/by/4.0/

(c) (i) Open Access

\section{Abstract}

2-ethylhexyl hydrogen-2-ethylhexylphosphonate (EHEP) is commonly used as a metal extractant because it has a particular affinity for rare-earth metals like Scandium (Sc). To develop a highly-selective adsorbent of Sc(III), EHEP was introduced as a functional group onto a polyethylene fabric with radiation-induced graft polymerization(RIGP). The adsorption performances for Sc(III) were evaluated with aqueous solutions containing Sc(III) and Fe(III) in bath and column tests. As a result of column test, the adsorption capacities of Sc(III) and Fe(III) until the bed volume reached 5000 were 5.22 and $0.12 \mathrm{mg} / \mathrm{g}$, respectively. It means that the amount of collected Sc(III) by the EHEP adsorbent was approximately 44 times higher than that of Fe(III). These results indicate that the grafted adsorbent containing EHEP has an extremely high selectivity for Sc(III) adsorption.

\section{Keywords}

Fibrous Adsorbent, Scandium, Radiation-Induced Graft Polymerization, Selective Adsorption, 2-Ethylhexyl Hydrogen-2-Ethylhexylphosphonate

\section{Introduction}

A fibrous adsorbent containing phosphoric acids which has a predilection for Scandium (Sc)(III) [1] [2], has

${ }^{*}$ Corresponding author.

How to cite this paper: Hoshina, H., Ueki, Y., Saiki, S. and Seko, N. (2014) Synthesis of Highly-Selective Fibrous Adsorbent by Introducing 2-Ethylhexyl Hydrogen-2-Ethylhexylphosphonate for Scandium Adsorption. International Journal of Organic Chemistry, 4, 195-200. http://dx.doi.org/10.4236/ijoc.2014.43022 
been investigated to recover Sc(III) from hot spring water [3]. The Sc(III) recovery was conducted with the adsorbent, which was prepared by introducing 2-hydroxyethyl methacrylate phosphoric acid (HMPA) into a nonwoven polyethylene fabric with radiation-induced graft polymerization (RIGP) [4], in Kusatsu Hot Springs in Gunma Prefecture [5]. The adsorbent containing HMPA could rapidly collect Sc(III) from hot spring water contained a low concentration of Sc(III). However, Fe(III) was also caught by the adsorbent unwillingly because the $\mathrm{Fe}(\mathrm{III})$ had dissolved at a 400 times higher than concentration of Sc(III) in hot spring water with acidic condition. To recover Sc(III) efficiently from hot spring water, a highly-selective adsorbent for Sc(III) was required.

2-ethylhexyl hydrogen-2-ethylhexylphosphonate (EHEP) is a superior metal extractant and is widely used in solvent extraction [6] [7]. EHEP has a particular affinity for rare-earth metals like Sc(III), especially in acid solutions [8]-[10]. If EHEP is able to be introduced into a polymeric material while maintaining its efficiency, it is possible to develop a highly-selective adsorbent for Sc(III).

RIGP is a useful technique to functionalize a polymeric material such as cellulose, polypropylene and polyethylene [11]-[13]. By using the RIGP technique, the functional groups can be introduced into the polymeric material without changing its characteristic dramatically. In the case of introducing the EHEP as a functional group, first dodecyl methacrylate (DMA) which has long-chain alkyl groups, was introduced with RIGP onto the polymeric material, and subsequent introduction of EHEP by hydrophobic interaction of long-chain alkyl groups in the DMA structure and that of EHEP (Figure 1).

In this article, the highly-selective adsorbent for Sc(III) was developed by introducing EHEP with RIGP technique, and evaluation of its adsorption performance for Sc(III) was carried out with an aqueous solution containing Sc(III) and Fe(III).

\section{Experimental}

\subsection{Materials}

A non-woven fabric composed of polyethylene coated polypropylene fiber was purchased from Kurashiki Textile Manufacturing Co., Ltd. to be used as a base material for the adsorbent. EHEP was provided by Daihachi Chemical Industry Co., Ltd.DMA, Tween 20, phosphoric acid and methanol were supplied by Kanto Chemical Co., INC. A monomer of GMA and HMPA were purchased from Tokyo Chemical Industry Co., Ltd. and Kyoeisha Chemical Co., Ltd., respectively. All chemicals were used without further purification.

\subsection{Preparation of the Adsorbent for Sc(III) Adsorption}

The non-woven fabrics were packed into polyethylene bags. Then, the inside of the bags were made into a nitrogen atmosphere with nitrogen gas, which were irradiated at the maximum dose of $500 \mathrm{kGy}$ with an electron beam accelerator under a dry ice temperature. The irradiated fabrics were placed into glass ampoules and were evacuated. A deoxidized monomer solution, which was a mix of DMA, Tween 20, and deionized water, was transferred into the ampoules. The concentrations of DMA and Tween 20 in the solution were 20\% and 2\% $(\mathrm{w} / \mathrm{w})$, respectively. The grafting of DMA was carried out at $60^{\circ} \mathrm{C}$ for 6 hours. After grafting, the grafted fabrics were washed with methanol to remove the residual DMA and homopolymer. The degree of grafting (Dg) was calculated by the following equation;

$$
\text { Degree of grafting }(D g)[\%]=\left(W_{1}-W\right)_{0} / W_{0} \times 100
$$

where $W_{0}$ and $W_{1}$ were the weight of fabrics before and after graft polymerization.

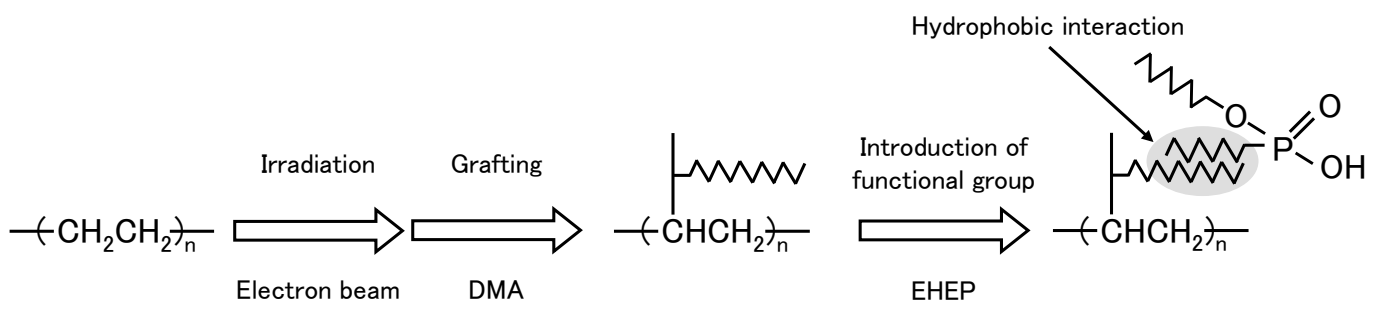

Figure 1. Preparation scheme of graft adsorbent containing EHEP. 
To introduce EHEP as a functional group by hydrophobic interaction of long-chain alkyl group in the DMA structure and that of EHEP, the grafted fabrics were soaked in EHEP, and were shaken for 12 hours at room temperature. The adsorbents introduced EHEP (EHEP adsorbent) were obtained after the residual EHEP was removed.

\subsection{Evaluation of the EHEP Adsorbent}

The adsorption performance of Sc(III) was evaluated with an aqueous solution containing Sc(III) and Fe(III) at concentrations $1 \mathrm{mg} / \mathrm{L}$ in batch and column adsorption tests. To compare the adsorption performance for Sc(III), two other types of adsorbents containing phosphoric acid as a functional group were prepared for batch adsorption tests. One of the adsorbents was prepared with RIGP of glycidyl methacrylate (GMA), and followed by chemical modification with phosphoric acid (GMA-PA adsorbent). Another adsorbent was synthesized by introducing HMPA with RIGP technique (HMPA adsorbent). The adsorbents were soaked in $50 \mathrm{~mL}$ of the aqueous solutions containing $\mathrm{Sc}(\mathrm{III})$ and Fe(III), and were stirred for 12 hours at room temperature. The solutions were adjusted to $\mathrm{pH}$ 0, 1, 2 and 3 with nitric acid. After the adsorption tests, the concentrations of Sc(III) and $\mathrm{Fe}(\mathrm{III})$ in the solutions were measured with induced coupled plasma atomic emission spectroscopy [ICPAES, Perkin Elmer Inc., Optima 4300DV]. In the column test, $0.08 \mathrm{~mL}$ of the EHEP adsorbent was packed into a $7 \mathrm{~mm}$ internal diameter column. The aqueous solution containing $\mathrm{Sc}(\mathrm{III})$ and $\mathrm{Fe}(\mathrm{III})$ was adjusted to $\mathrm{pH} 1$, then it was delivered to the column at the flow rate of space velocity (SV) $250 \mathrm{~h}^{-1}$.

\section{Results and Discussion}

\subsection{Preparation of the Adsorbent for Sc(III) Adsorption}

The RIGP of DMA was conducted with 20\% (w/w) of the DMA solution for 6 hours at absorbed dose of 20, 30, 50 100, 200 and $500 \mathrm{kGy}$. The effect of the absorbed dose on the Dg was shown in Figure 2. The Dg increased simultaneously with the absorbed dose. The Dg reached 120\% at the absorbed dose of $500 \mathrm{kGy}$. To introduce EHEP as a functional group, the grafted fabric of Dg 120\% was soaked into EHEP for 12 hours and consequently the EHEP adsorbent with the density of $1.0 \mathrm{mmol} / \mathrm{g}$ was obtained. The adsorbent was analyzed by using a spectrum one FT-IR spectrometer [Perkin Elmer Co., Ltd.]. As shown in Figure 3, the FTIR spectrum of the EHEP adsorbent showed a new characteristic adsorption band of EHEP at around 1240 $\mathrm{cm}^{-1}$, which was due to the double bond between the phosphorus and oxygen, in addition to the same adsorption band of the base material. This result confirmed the presence of EHEP in the adsorbent.

\subsection{Evaluation of the EHEP Adsorbent}

The effect of $\mathrm{pH}$ on the Sc(III) adsorption with Fe(III) coexisting was investigated at pH 0, 1, 2 and 3 with the three types of adsorbent containing phosphoric acid groups. As shown in Table 1, the EHEP adsorbent had the high adsorption capacity more than $6.5 \mathrm{mg} / \mathrm{g}$ for Sc at any $\mathrm{pH}$. In the case of the GMA-PA adsorbent, the adsorption capacity of Sc(III) increased with decreasing the $\mathrm{pH}$, and the maximum capacity was $3.9 \mathrm{mg} / \mathrm{g}$ at $\mathrm{pH} 0$. The HMPA adsorbent had an adsorption capacity of approximately $1 \mathrm{mg} / \mathrm{g}$ at the $\mathrm{pH}$ of 0 to 4 . As a result, the EHEP adsorbent showed a high adsorption capacity of more than double in comparison with the two other types of adsorbent at any pH. The adsorption capacity of Fe(III) increased as the pH increased with every type of adsorbent. The selectivity of Sc(III) adsorption was evaluated as follows,

$$
\text { Adsorption } \operatorname{ratio}(R)[\%]=\left(C_{0}-C_{1}\right) / C_{0} \times 100
$$

where $C_{0}$ and $C_{1}$ were the concentration of the $\mathrm{Sc}(\mathrm{III})$ and $\mathrm{Fe}(\mathrm{III})$ in solution before and after adsorption.

$$
\text { Selectivity of } \mathrm{Sc}(\mathrm{III})(S)[-]=R_{S c}-R_{F e}
$$

where $R_{S c}$ and $R_{F e}$ were the adsorption ratio of Sc(III) and Fe(III), respectively.

The selectivity for Sc(III) versus Fe(III) of the EHEP, GMA-PA and HMPA adsorbents were presented in Figure 4. In this figure, the Y-axis is the selectivity for Sc(III). For example, if the selectivity of Sc(III) reached 100 , all of the Sc(III) in the solution was adsorbed and Fe(III) was not adsorbed at all. If the selectivity of Sc(III) was less than 0, the adsorption ratio of Sc(III) was lower than that of Fe(III). As shown in Figure 4, the selectivity of Sc(III) increased by decreasing the $\mathrm{pH}$ in all types of adsorbent. Compared with two other types of adsor-- 


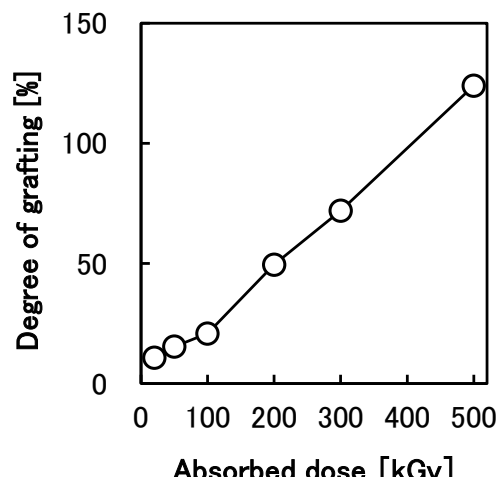

Figure 2. Effect of absorbed dose on the degree of grafting.

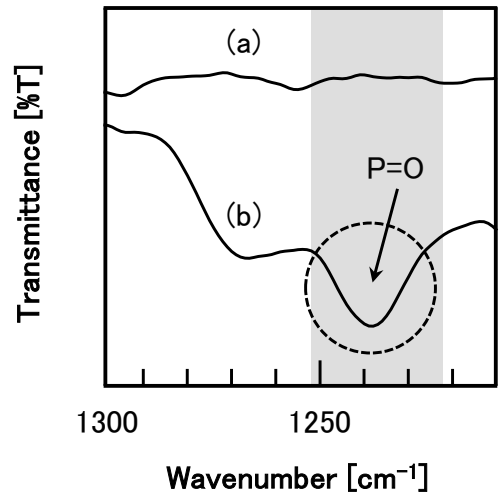

Figure 3. FTIR spectra of base material (a) and the EHEP adsorbent (b).

Table 1. Effect of pH on the adsorption capacity of Sc(III) and Fe(III).

\begin{tabular}{|c|c|c|c|c|c|c|c|c|c|}
\hline \multirow{4}{*}{ adsorbent } & \multirow{4}{*}{$\begin{array}{c}\text { Density of } \\
\text { functional } \\
\text { groups } \\
{[\mathrm{mmol} / \mathrm{g}]}\end{array}$} & \multicolumn{8}{|c|}{$\mathrm{pH}$} \\
\hline & & \multicolumn{2}{|c|}{0} & \multicolumn{2}{|c|}{1} & \multicolumn{2}{|c|}{2} & \multicolumn{2}{|c|}{3} \\
\hline & & \multicolumn{2}{|c|}{ Adsorption capacity } & \multicolumn{2}{|c|}{ Adsorption capacity } & \multicolumn{2}{|c|}{ Adsorption capacity } & \multicolumn{2}{|c|}{ Adsorption capacity } \\
\hline & & $\begin{array}{l}\mathrm{Sc}(\mathrm{III}] \\
{[\mathrm{mg} / \mathrm{g}]}\end{array}$ & $\begin{array}{l}\mathrm{Fe}(\mathrm{III}] \\
{[\mathrm{mg} / \mathrm{g}]}\end{array}$ & $\begin{array}{l}\mathrm{Sc}(\mathrm{III}] \\
{[\mathrm{mg} / \mathrm{g}]}\end{array}$ & $\begin{array}{l}\mathrm{Fe}(\mathrm{III}] \\
{[\mathrm{mg} / \mathrm{g}]}\end{array}$ & $\begin{array}{l}\text { Sc(III] } \\
{[\mathrm{mg} / \mathrm{g}]}\end{array}$ & $\begin{array}{l}\mathrm{Fe}(\mathrm{III}] \\
{[\mathrm{mg} / \mathrm{g}]}\end{array}$ & $\begin{array}{l}\mathrm{Sc}(\mathrm{III}] \\
{[\mathrm{mg} / \mathrm{g}]}\end{array}$ & $\begin{array}{l}\mathrm{Fe}(\mathrm{III}] \\
{[\mathrm{mg} / \mathrm{g}]}\end{array}$ \\
\hline EHEP & 1.0 & 7.45 & 0.21 & 6.52 & 0.44 & 7.99 & 1.79 & 7.32 & 3.79 \\
\hline GMA-PA & 1.3 & 3.93 & 1.67 & 2018 & 1.68 & 1.74 & 2.21 & 1.04 & 2.71 \\
\hline HMPA & 1.4 & 1.42 & 0.16 & 0.82 & 0.15 & 1.22 & 0.95 & 1.03 & 1.90 \\
\hline
\end{tabular}

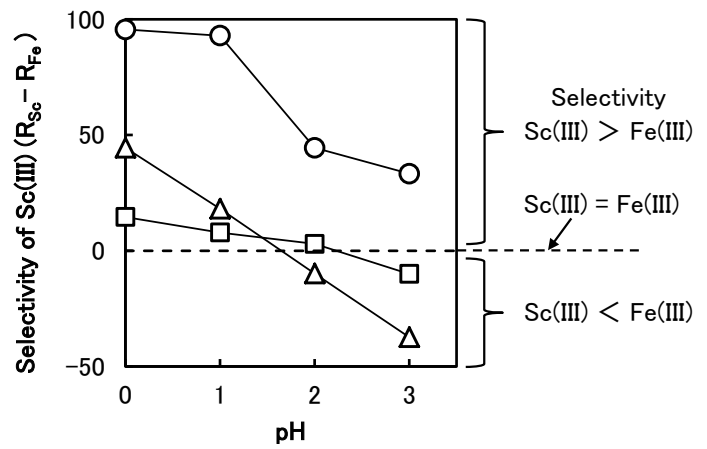

Figure 4. Effect of $\mathrm{pH}$ on the adsorption selectivity for Sc(III) versus Fe(III) of EHEP (O), GMA-PA $(\triangle)$ and HMPA $(\square)$. 


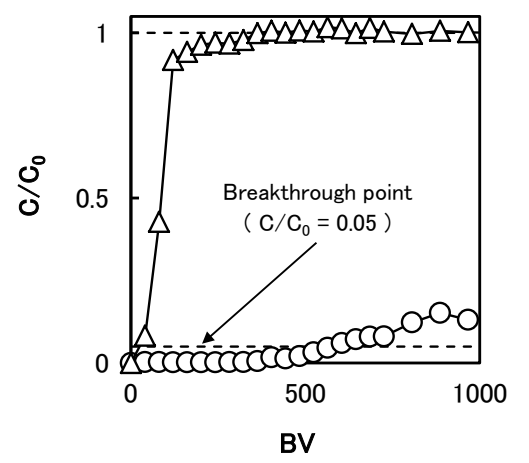

Figure 5. The breakthrough curves of Sc(III) (O) and Fe(III)

$(\triangle)$ with the mixture solution of Sc(III)and Fe(III) at $\mathrm{pH} 1$.

bents, the EHEP adsorbent showed an extremely high selectivity for Sc(III) at any $\mathrm{pH}$. The selectivity of Sc(III) reached higher than 90 in strongly acidic conditions ( $\mathrm{pH} 0$ and 1). Therefore, the column mode adsorption test was carried out with the aqueous solutions containing $\mathrm{Sc}(\mathrm{III})$ and $\mathrm{Fe}(\mathrm{III})$ adjusted to $\mathrm{pH} 1$.

The breakthrough curves of Sc(III) and Fe(III) adsorption were shown in Figure 5. The breakthrough curve was obtained by plotting $C / C_{0}$ which was the concentration of $\mathrm{Sc}(\mathrm{III})$ and $\mathrm{Fe}(\mathrm{III})$ in the feeding solution $\left(C_{0}\right)$ and the effluent $(C)$ versus bed volume (BV). The breakthrough point was defined when $C / C_{0}$ reached 0.05 . The breakthrough point of Sc(III) adsorption was BV 564. The $C / C_{0}$ of Sc(III) gradually increased incrementally in $\mathrm{BV}$, and reached 0.78 at $\mathrm{BV} 5000$. In the case of $\mathrm{Fe}(\mathrm{III})$ adsorption, the $C / C_{0}$ exceeded the breakthrough point immediately following the start of the adsorption test, and reached 1.00 at BV 362. The adsorption capacities of Sc(III) and Fe(III) until the BV reached 5000 were 5.22 and $0.12 \mathrm{mg} / \mathrm{g}$, respectively. It means that the amount of collected Sc(III) by the EHEP adsorbent was approximately 44 times higher than that of Fe(III). These results established that the EHEP adsorbent could collect Sc(III) selectively from a strongly acidic water media.

\section{Conclusion}

The highly-selective fibrous adsorbent for Sc(III) was developed by RIGP of DMA and subsequent introduction of EHEP as a functional group by hydrophobic interaction of long-chain alkyl group in the DMA structure and that of EHEP. The EHEP adsorbent exhibited a high adsorption capacity and selectivity for Sc(III) in acidic conditions compared with other types of the adsorbents containing phosphoric acid groups. In the case of column mode adsorption test using an aqueous solution containing $\mathrm{Sc}(\mathrm{III})$ and $\mathrm{Fe}(\mathrm{III})$ at $\mathrm{pH}$ 1, the adsorption capacity of Sc(III) with the EHEP was 44 times higher than that of Fe(III). It meant that the EHEP adsorbent could collect only Sc(III) mostly without Fe(III) adsorption. If the EHEP adsorbent is able to be applied for the Sc(III) recovery from hot spring water, it will be achieved the practical use of the Sc(III) recovery and hot spring will be a new resource of Sc.

\section{References}

[1] Marhol, M., Beranova, H. and Cheng, K.L. (1974) Selective Ion-Exchangers Containing Phosphorus in Their Functional Groups. Journal of Radioanalytical Chemistry, 21, 177-186. http://dx.doi.org/10.1007/BF02520860

[2] Hubicki, Z. (1990) Studies on Selective Separation of Sc(III) from Rare Earth Elements on Selective Ion-Exchangers. Hydrometallurgy, 23, 319-331. http://dx.doi.org/10.1016/0304-386X(90)90013-R

[3] Kasai, N., Seko, N., Tamada, M. and Ichikawa, E. (2006) The Recovery Method of Scandium from Hot Spring Water. JAEA-Review 2006-042, 46.

[4] Kabanov, V.Y., Aliev, R.E. and Kudryavtsev, V.N. (1991) Present Status and Development Trends of Radiation-Induced Graft Polymerization. Radiation Physics and Chemistry, 37, 175-192.

[5] Seko, N., Hoshina, H., Kasai, N., Ueki, Y. and Tamada, M. (2010) Novel System for Recovering Scandium from Hot Spring Water with Fibrous Graft Adsorbent. Journal of Ion Exchange, 21, 117-122.

[6] Jayachandran, J. and Dhadke, P.M. (1997) Liquid-Liquid Extraction Separation of Ion(III) with 2-Ethyl Hexyl Phosphonic Acid Mono 2-Ethylhexyl Ester. Talanta, 44, 1285-1290. http://dx.doi.org/10.1016/S0039-9140(97)02190-5

[7] Bandekar, S.V. and Dhadke, P.M. (1998) Solvent Extraction Separation of Tin (IV) with 2-Ethylhexyl Phosphonic 
Acid Mono-2-Ethylhexyl Ester. (PC-88A). Talanta, 46, 1181-1186. http://dx.doi.org/10.1016/S0039-9140(97)00364-0

[8] Surampally, R., Batchu, N.K, Mannepalli, L.K. and Bontha, R.R. (2012) Studies on Solvent Extraction of Dy(III) and Separation Possibilities of Rare Earths Using PC-88A from Phosphoric Acid Solutions. Journal of the Taiwan Institute of Chemical Engineers, 43, 839-844. http://dx.doi.org/10.1016/j.jtice.2012.04.009

[9] Thakur, N.V., Jayawant, D.V., Iyer, N.S. and Koppiker, K.S. (1993) Separation of Neodymium from Lighter Rare Earths Using Alkyl Phosphonic Acid, PC 88A. Hydrometallurgy, 34, 99-108. http://dx.doi.org/10.1016/0304-386X(93)90084-Q

[10] Wakui, Y., Matsunaga, H. and Suzuki, T.M. (1989) Selective Recovery of Trace Scandium from Acid Aqueous Solution with (2-Ethylhexyl Hydrogen 2-Ethylhexylphosphonate)-Impregnated Resin. Analytical Sciences, 5, 189-193. http://dx.doi.org/10.2116/analsci.5.189

[11] Hoshina, H., Takahashi, M., Kasai, N. and Seko, N. (2012) Adsorbent for Arsenic (V) Removal Synthesized by Radiation-Induced Graft Polymerization onto Nonwoven Cotton Fabric. International Journal of Organic Chemistry, 2, 173177. http://dx.doi.org/10.4236/ijoc.2012.23026

[12] Bondar, Y., Kim, H.J. Yoon, S.H. and Lim, Y.J. (2004) Synthesis of Cation-Exchange Adsorbent for Anchoring Metal Ions by Modification of Poly (Glycidyl Methacrylate) Chains Grafted into Polypropylene Fabric. Reactive \& Functional Polymers, 58, 43-51. http://dx.doi.org/10.1016/j.reactfunctpolym.2003.11.006

[13] Ueki, Y., Dafader, N.C, Hoshina, H. Seko, N. and Tamada, M. (2012) Study and Optimization on Graft Polymerization under Normal Pressure and Air Atmospheric Conditions, and Its Application to Metal Adsorbent. Radiation Physics and Chemistry, 81, 889-898. http://dx.doi.org/10.1016/j.radphyschem.2012.02.031 
Scientific Research Publishing (SCIRP) is one of the largest Open Access journal publishers. It is currently publishing more than 200 open access, online, peer-reviewed journals covering a wide range of academic disciplines. SCIRP serves the worldwide academic communities and contributes to the progress and application of science with its publication.

Other selected journals from SCIRP are listed as below. Submit your manuscript to us via either submit@scirp.org or Online Submission Portal.
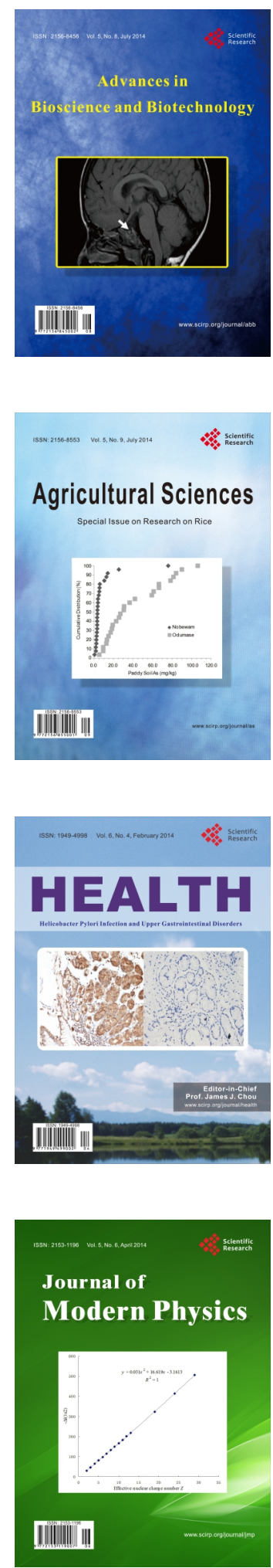
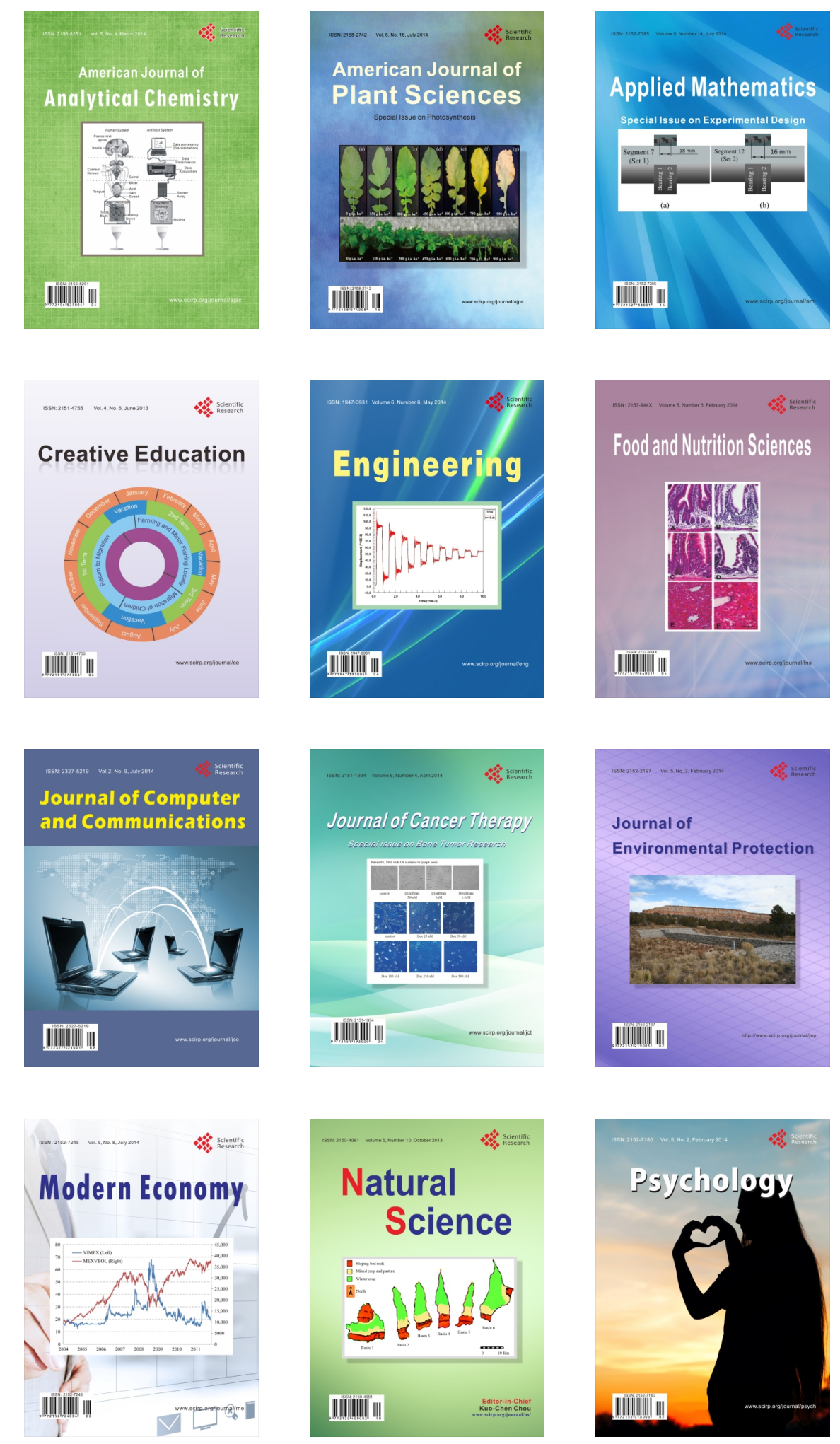